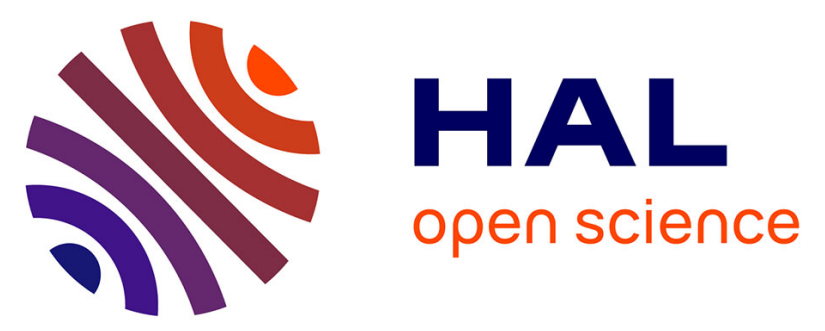

\title{
Gas phase and surface kinetics in plasma and hot filament-enhanced catalytic chemical vapor deposition of carbon nanostructures
}

Francois Le Normand, M. Gulas, Pavel Veis, Costel Sorin Cojocaru, Jean Eric Bourée

\section{To cite this version:}

Francois Le Normand, M. Gulas, Pavel Veis, Costel Sorin Cojocaru, Jean Eric Bourée. Gas phase and surface kinetics in plasma and hot filament-enhanced catalytic chemical vapor deposition of carbon nanostructures. Thin Solid Films, 2009, 517 (12), pp.3466-3471. 10.1016/j.tsf.2009.01.079 . hal00794994

\section{HAL Id: hal-00794994 \\ https://hal.science/hal-00794994}

Submitted on 28 Feb 2013

HAL is a multi-disciplinary open access archive for the deposit and dissemination of scientific research documents, whether they are published or not. The documents may come from teaching and research institutions in France or abroad, or from public or private research centers.
L'archive ouverte pluridisciplinaire HAL, est destinée au dépôt et à la diffusion de documents scientifiques de niveau recherche, publiés ou non, émanant des établissements d'enseignement et de recherche français ou étrangers, des laboratoires publics ou privés. 


\title{
Thin Solid Films \\ 517 (2009) 3466-3471 \\ DOI: http://dx.doi.org/10.1016/j.tsf.2009.01.079
}

\section{Gas phase and surface kinetics in plasma and hot filament-enhanced catalytic chemical vapor deposition of carbon nanostructures}

\author{
F. Le Normand ${ }^{\text {a, }}$, M. Gulas ${ }^{\text {a,b }}$, P. Veis ${ }^{b}$, C.S. Cojocaru ${ }^{\text {c }}$, J.E. Bourée ${ }^{\text {c }}$ \\ a Institut de Physique et Chimie des Matériaux de Strasbourg / Groupe Surfaces et Interfaces, CNRS UMR 7504, Université Louis Pasteur, 67034 Strasbourg cedex 2, France \\ b Department of Experimental Physics, Faculty of Mathematics, Physics and Informatics, Comenius University, Mlynska dolina, Bratislava 84215, Slovakia \\ ${ }^{c}$ Laboratoire de Physique des Interfaces et des Couches Minces, CNRS UMR 7647, Ecole Polytechnique, 91128 Palaiseau, France
}

\section{Keywords:}

Hot-wire chemical vapor deposition

Carbon nanotubes

Gas phase kinetics

Surface kinetics

\begin{abstract}
A B S T A RCT
Simulations of the gas phase chemistry $\left(\mathrm{C}_{2} \mathrm{H}_{2} / \mathrm{H}_{2}\right)$ coupled with surface reactions for the catalytic growth of carbon nanostructures (nanotubes/nanofibers), using different activation modes of catalytic chemical vapor deposition (CCVD) process, are presented. Deposits issued from thermal CCVD, hot-filament CCVD, plasma- enhanced CCVD and plasmaenhanced combined with hot-filament CCVD are compared to simulations of the gas phase and surface kinetics. The influence of the activation elements is described in detail. According to these simulations taking into account optical emission spectroscopy data, gas phase composition and linear growth rate of tubular nanostructures are predicted in good agreement with the experimental observations.
\end{abstract}

1. Introduction

Carbon nanotubes (CNTs) are mainly synthesized by electric arc discharge, laser ablation or catalytic chemical vapor deposition. The first two methods which are high temperature methods, involve sublimating graphite in a reduced atmosphere of rare gases brought to a temperature above $3000 \mathrm{~K}$. In these conditions, monomers $\mathrm{C}$, dimers $\mathrm{C}_{2}$ and trimers $\mathrm{C}_{3}$ are considered as precursors for nanotube formation $[1,2]$. On the other hand, the third method, a medium-temperature route (b $1000{ }^{\circ} \mathrm{C}$ ), was the synthesis way to filamentous carbon used in the sixties, and seems promising due to its flexibility and its facility to be scaled up. In this method, carbon nanotubes or carbon nanofibers are grown through the interaction of metal-catalyst nanoparticles with hydrocarbon vapor at temperatures around $600-700{ }^{\circ} \mathrm{C}$. The hydrocarbon molecules dissociate at the interface between catalyst and vapor, and carbon atoms precipitate into a graphite trail in the shape of a cylindrical, multi-walled nanotube. However there is still debate about the nanotube/nanofiber growth mechanisms. The commonly accepted growth model suggests that: (i) carbon-containing compounds adsorb dissociatively at the surface of metal nanoclusters; (ii) carbon dissolves in the bulk of the cluster; (iii) carbon diffuses through the bulk of the nanocluster to the rear end, where (iv) the carbon atoms are incorporated into the new graphene layers of the growing nanofiber [3,4]. A recent study using in situ time-resolved TEM observations revealed that the nucleation and growth of graphene layers are associated with the dynamic formation and restructuring of monoatomic step-edges at the nickel surface, these observations being consistent with a growth model involving surface transport of carbon and nickel atoms along the graphene-nickel interface [5]. However, besides approaches enabling elucidation of basic mechanisms, it is also necessary to establish relationships between the fabrication-process parameters and the nucleation and growth conditions of the growing nanotubes/nanofibers. For instance several studies have been performed on the role of metal nanoparticles in the CVD processes with respect to various parameters (particle size, concentration gradient,... [6-8]). However few papers have been devoted to the study of gas phase kinetics [9-11] and surface kinetics [12,13].

In this paper, growth of CNTs using different CCVD activation modes is discussed in detail. Thus experimental results based on thermal CCVD, hot-filament (HF) CCVD, plasma-enhanced (PE) CCVD and plasma-enhanced hot-filament (PE HF) CCVD are presented. These results are compared to simulations of absolute concentrations of carbon species. These simulations account for OES data and a set of reactions from gas phase kinetics and surface chemistry.

\section{Experimental details}

Ultra high vacuum chemical vapor deposition (UHV CVD) experimental apparatus, shown in Fig. 1, consists of three elements of gas phase activation. Two pairs of tungsten wires are placed at distances $5 \mathrm{~mm}$ and $10 \mathrm{~mm}$ parallel to the substrate. A direct current glow discharge as primary plasma is ignited between two electrodes located on each side of the highest wires and an extraction plasma is created by introducing an additional small biasing between the lowest electrode of the primary plasma cathode and the sample. Then a negative glow appears $1.5 \mathrm{~mm}$ above the sample. Finally the gas phase and the sample are also heated by an infra-red halogen lamp set at $8 \mathrm{~mm}$ below the substrate, the heating being focused on the sample on 



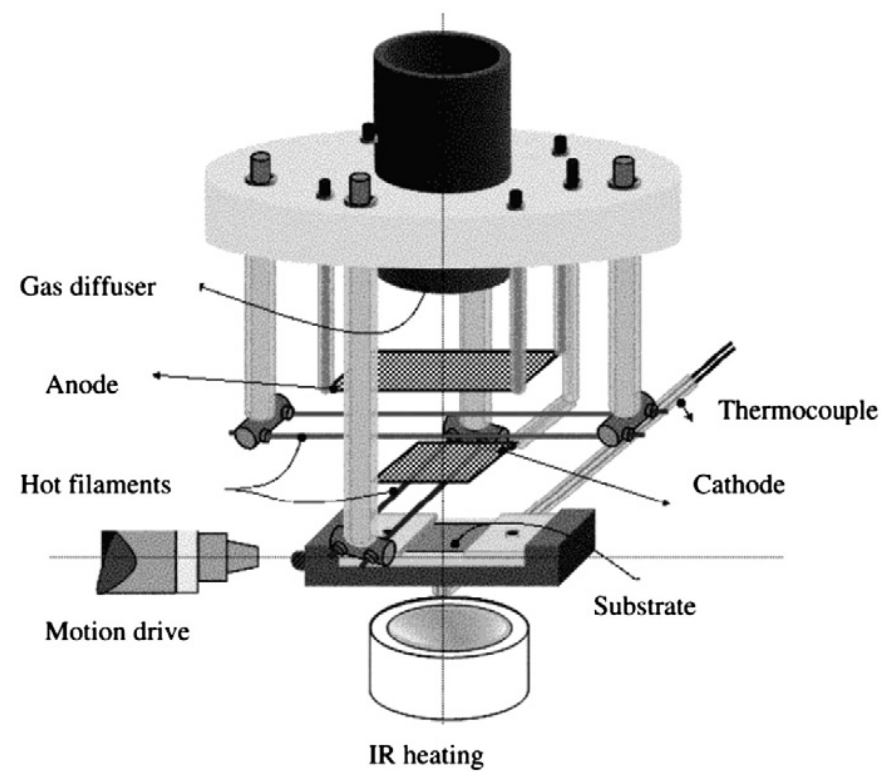

Fig. 1. Experimental apparatus.

around $10 \times 10 \mathrm{~mm}^{2}$. This experimental set-up along with several modifications has been used for synthesis of diamond [14], multiwalled carbon nanotubes (MWCNTs) [15], double-walled carbon nanotubes and other carbon nanostructures [16].

Therefore the CVD chamber can be used in four different CVD modes. Thermal CCVD is obtained using IR lamps, which directly heat the sample at $973 \mathrm{~K}$. In this type of synthesis, activation process occurs mainly on the substrate, where hydrocarbon molecules are decomposed by the catalytic particles. Whatever the activation mode is, the heating lamp is used to maintain the desired growth temperature at the sample. In the HF CCVD mode, the incoming gas is activated by tungsten filaments heated at $2223 \mathrm{~K}$, which act as catalysts above the sample. This allows a large decomposition of molecular hydrogen and other hydrocarbon species into radicals. In PE CCVD, the incoming gas is activated by the dc glow discharge. Temperature of the plasma is dependent on the partial pressure of the gas precursors, but in standard conditions described further on, the gas temperature was around $1300 \mathrm{~K}$, as measured by optical emission spectroscopy [17]. In the last mode, PE HF CCVD, the gas is now activated by the hot filaments, by the dc glow discharge and by the thermal heating of the sample surface.

Synthesis conditions for CCVD are identical for the different CCVD modes: pressure $\mathrm{p}_{\mathrm{g}}$ is $10 \mathrm{mbar}$, substrate temperature $\mathrm{T}_{\mathrm{s}}$ is $973 \mathrm{~K}$, total gas inlet $Q$ is 100 sccm with a $\mathrm{C}_{2} \mathrm{H}_{2} / \mathrm{H}_{2}(20 / 80)$ mixture, growth time $\mathrm{t}$ is 15 min. For the HF CCVD and PE HF CCVD modes, the filament temperature $T_{\mathrm{f}}$ is fixed at $2223 \mathrm{~K}$, as ascertained with a bichromatic optical pyrometer. For the PE CCVD and PE HF CCVD modes, the plasma power $\mathrm{P}_{\mathrm{p}}$ is about $1 \mathrm{~W}$, corresponding to $3.5 \mathrm{~mA}$ dc current on the sample and $300 \mathrm{~V}$ primary plasma potential. Co catalyst nanoparticles with size distribution around $10-15 \mathrm{~nm}$ are obtained by ultra high vacuum evaporation on the substrates consisting of Si (100) covered with a thin layer $(5 \mathrm{~nm})$ of $\mathrm{SiO}_{2}$ followed by a thermal annealing in specific conditions. Growth rates are experimentally estimated from SEM oblique observation on an edge of the carbon films. The rate of carbon incorporation from the catalyst is taken as simulated growth rate.

\section{Simulations}

Simulations of the $\mathrm{C}_{2} \mathrm{H}_{2} / \mathrm{H}_{2}$ and $\mathrm{C}_{2} \mathrm{H}_{2} / \mathrm{H}_{2} / \mathrm{NH}_{3}$ systems are performed by CHEMKIN ${ }^{\circledR}$ collection of softwares [18]. For all different types of CCVD, the SPIN, AURORA and EQUILIBRIUM codes are used. A detailed account of the model equations is given in [19]. EQUILIBRIUM software is used to calculate the initial conditions. The composition of the plasma at equilibrium is modeled using the AURORA software which assumes two temperatures, translational/rotational $\mathrm{T}_{\mathrm{g}}$ and electronic $T_{\mathrm{e}}$, each describing a Maxwell-Boltzmann distribution for its respective mode. In one dimension (1D), the SPIN code is used to calculate the distribution of gas phase and surface species in the CCVD reactor.

Simulated temperature profile for CCVD reactor is coupled with OES measurements of the plasma [17] in PE HF CCVD mode and with the plasma heating [20] in PE CCVD mode. The temperature profiles for the four CCVD activation modes are shown in Fig. 2. We observe that these modes separate out along two ways. In the first one, including thermal CCVD and PE CCVD modes, the gas temperature is not far from the substrate temperature $(973 \mathrm{~K})$, higher in the case of

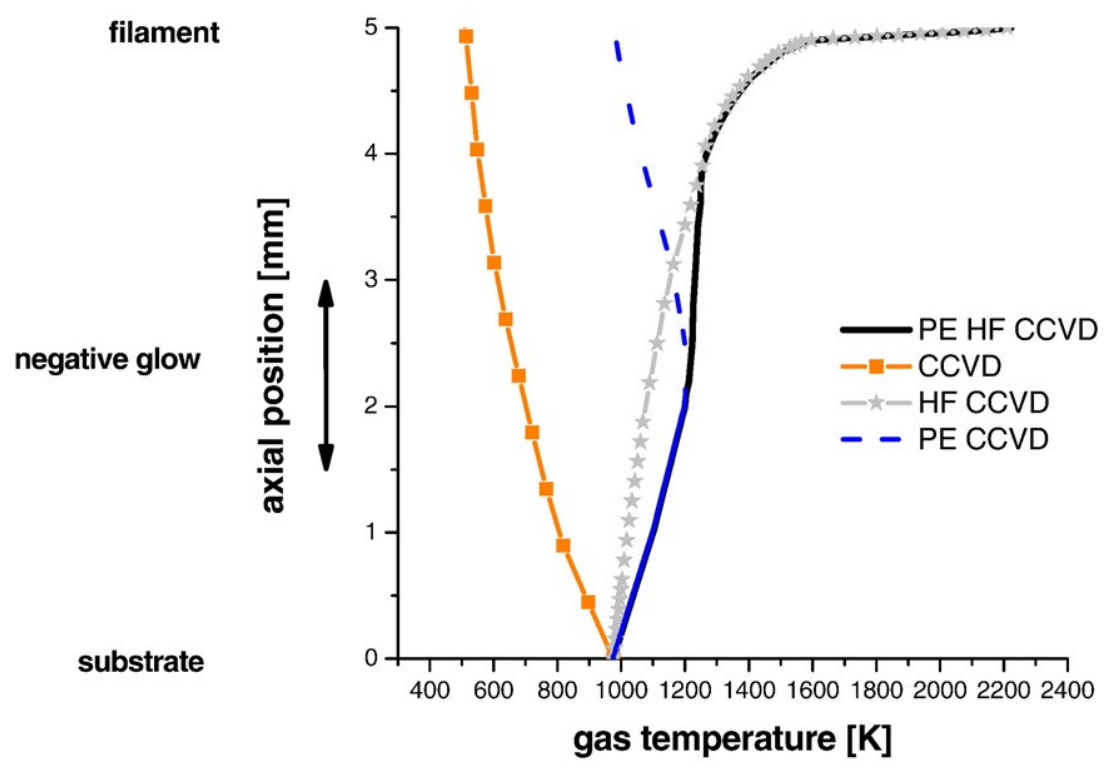

Fig. 2. Temperature profiles versus axial position in the CVD chamber. Substrate temperature is fixed at $973 \mathrm{~K}$. Ordinate origin is the sample position and the lower filament is set at $5 \mathrm{~mm}$ above the sample. 
(a)

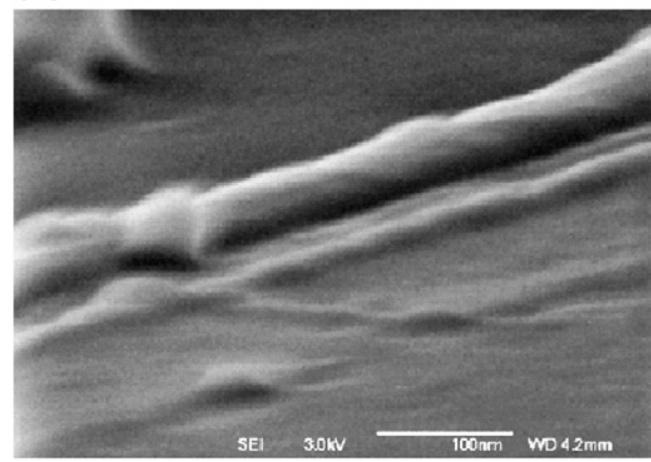

(c)

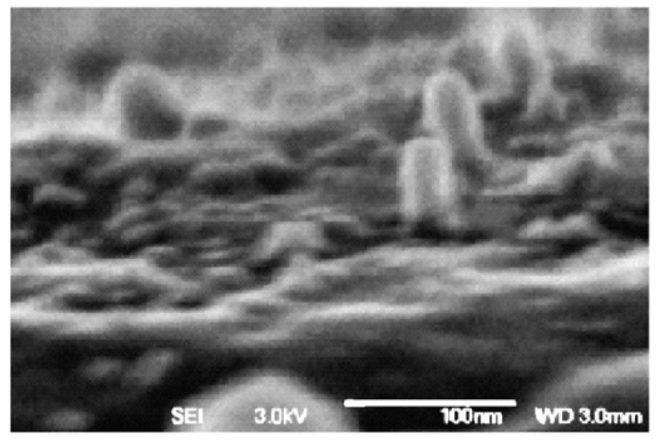

(b)

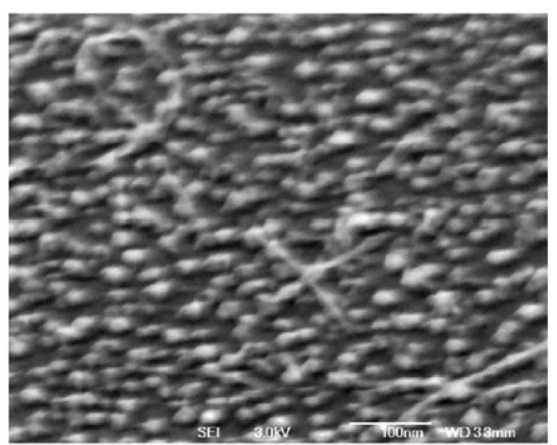

(d)

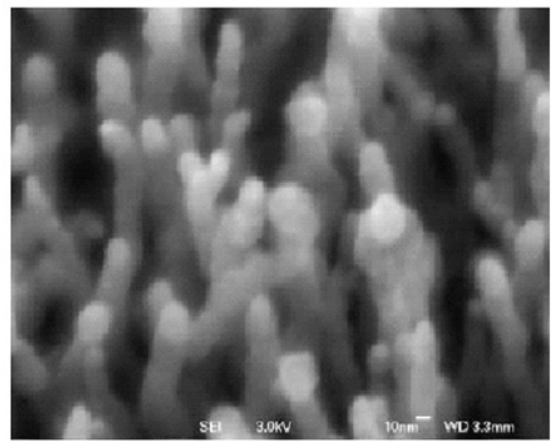

Fig. 3. SEM images of deposits synthesized in the same operating conditions with different activation modes: (a) Thermal CCVD; (b) HF CCVD; (c) PE CCVD; (d) PE HF CCVD.

PE due to the heating of the gas phase species by the plasma, lower in the case of thermal, the difference between both reaching around $400 \mathrm{~K}$. The second way of activation mode including HF CCVD and PE HF CCVD occurs when the hot filaments are switched on: then the filament temperature reaches $2300 \mathrm{~K}$. In that case, the difference in the temperature profiles due to plasma heating does not exceed $100 \mathrm{~K}$. The gas temperature profile $T_{g}(d)$ in the region extending from the filaments to the substrate is taken from Mankelevich et al. [21] who deduced their result from similar $\mathrm{CH}_{4} / \mathrm{H}_{2}$ or $\mathrm{C}_{2} \mathrm{H}_{2} / \mathrm{H}_{2}$ gas mixture configurations used for diamond growth:

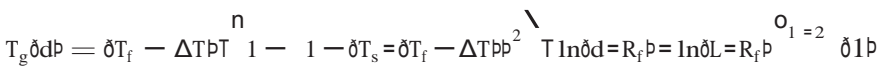

where $\Delta \mathrm{T}$ is the temperature drop at the filament surface set at $450 \mathrm{~K}$ from OES measurement, $\mathrm{L}$ and $\mathrm{R}_{\mathrm{f}}$ are the respective filament-substrate

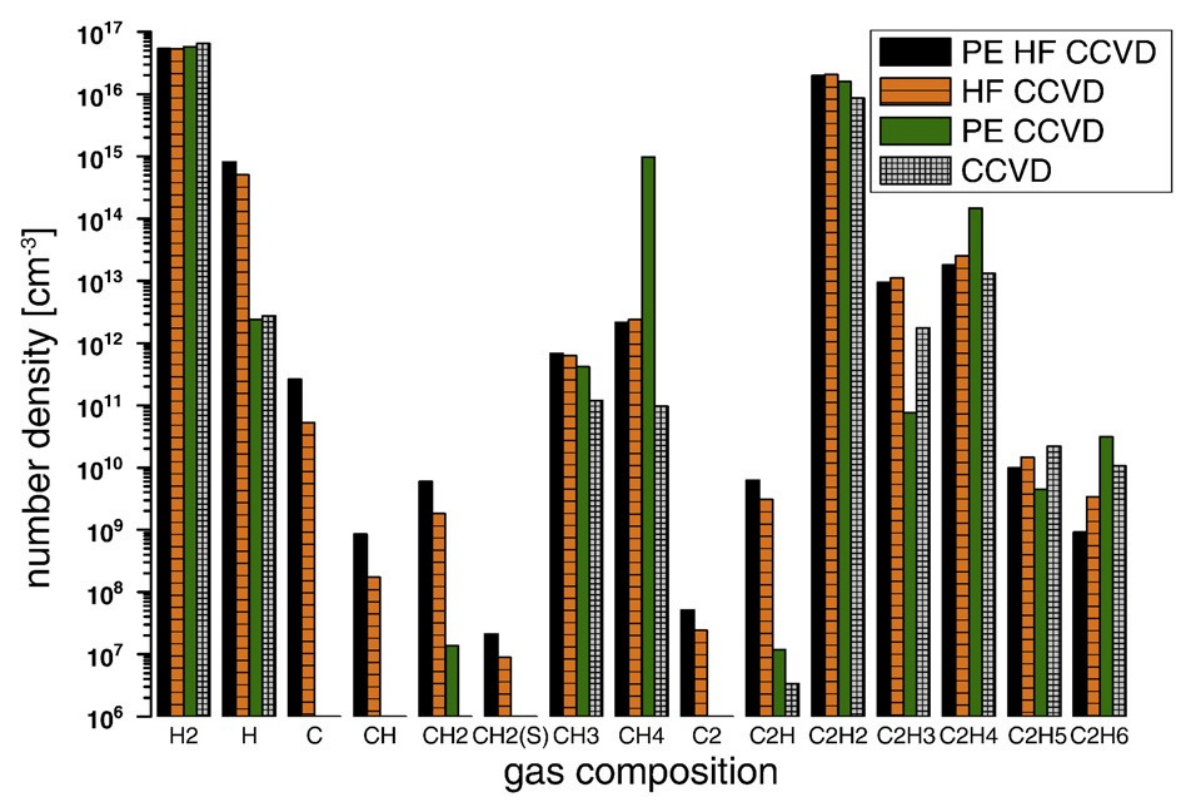

Fig. 4. Simulated gas composition (inlet mixture $\mathrm{C}_{2} \mathrm{H}_{2} / \mathrm{H}_{2}$ ) close to the substrate for different CVD modes. 
Table 1

Experimental $G_{\text {exp }}$ and simulated growth rates $G_{\text {sim }}$ for different activation modes.

\begin{tabular}{lllc}
\hline CCVD mode & Experimental growth rate $G_{\text {exp }}$ & & Simulated growth rate $G_{\text {sim }}$ \\
\cline { 2 - 2 } & {$[\mu \mathrm{m} / \mathrm{min}]$} & & $\left.10^{-3} / \mathrm{min}\right]$ \\
\hline Thermal CCVD & $5 \times 10^{-4}$ & 0.5 \\
HF CCVD & 0 (this work) & \\
PE CCVD & $40[25]$ & $9 \times 10^{-3}$ \\
PE HF CCVD & $5 \times 10^{-3}$ & 0.4 & 0.8 \\
\hline
\end{tabular}

distance $(5 \mathrm{~mm})$ and filament radius $(150 \mu \mathrm{m})$. We must note however that the reactions at the filament surface are neglected.

Gas phase chemistry is modeled using more than 140 reactions involving 31 species distributed as 15 neutral species $\left[\mathrm{H}, \mathrm{H}_{2}, \mathrm{C}, \mathrm{CH}\right.$, $\mathrm{CH}_{2}, \mathrm{CH}_{2}$ (singlet), $\left.\mathrm{CH}_{3}, \mathrm{CH}_{4}, \mathrm{C}_{2}, \mathrm{C}_{2} \mathrm{H}, \mathrm{C}_{2} \mathrm{H}_{2}, \mathrm{C}_{2} \mathrm{H}_{3}, \mathrm{C}_{2} \mathrm{H}_{4}, \mathrm{C}_{2} \mathrm{H}_{5}, \mathrm{C}_{2} \mathrm{H}_{6}\right]$ for CCVD and HF CCVD modes and 16 extra charged species $\left[\mathrm{e}^{-}, \mathrm{H}^{-}, \mathrm{H}^{+}\right.$, $\mathrm{H}_{2}^{+}, \mathrm{C}^{+}, \mathrm{CH}^{+}, \mathrm{CH}_{2}^{+}, \mathrm{CH}_{3}^{+}, \mathrm{CH}_{4}^{+}, \mathrm{C}_{2}^{+}, \mathrm{C}_{2} \mathrm{H}^{+}, \mathrm{C}_{2} \mathrm{H}_{2}^{+}, \mathrm{C}_{2} \mathrm{H}_{3}^{+}, \mathrm{C}_{2} \mathrm{H}_{4}^{+}, \mathrm{C}_{2} \mathrm{H}_{5}^{+}$, $\mathrm{C}_{2} \mathrm{H}_{6}^{+}$] for PE CCVD and PE HF CCVD modes, respectively. A set of the reactions is presented in [19] where the same mixture of $\mathrm{C}_{2} \mathrm{H}_{2} / \mathrm{H}_{2}$ was used for investigation of plasma composition in similar synthesis conditions. In the case of the $\mathrm{C}_{2} \mathrm{H}_{2} / \mathrm{H}_{2} / \mathrm{NH}_{3}$ system, 200 reactions involving 45 species distributed as 29 neutral species and the same 16 charged species were necessary.

Surface reactions were taken from the model presented by Grujicic et al. [12] and extended to employ more hydrocarbon species which are believed to participate to the CNT growth. This model is based on chemisorption of hydrocarbon molecules on catalyst surface, hydrogen abstraction and diffusion of carbon atoms followed by formation of CNT.

\section{Results}

Scanning electron microscopy images of products synthesized by thermal CCVD, HF CCVD, PE CCVD and PE HF CCVD are shown in Fig. 3. Shortly, in our conditions, vertically aligned multi-walled carbon nanotubes were grown by the PE HF CCVD method (Fig. 3d), as confirmed by transmission electron microscopy and Raman spectroscopy (not shown) whereas some tiny tubular structures were grown by the PE CCVD method (Fig. 3c). When thermal CCVD (Fig. 3a) and HF CCVD (Fig. 3b) are carried out, catalytic nanoparticles encapsulated with turbostatic carbon are then produced, respectively. These observations are in disagreement with some other experiments in the literature, where nanotubes were produced also by thermal CCVD [22,23] and by HF CCVD [24,25]. However, we must keep in mind the different conditions used in the synthesis processes in these reports, for instance pressure.

Our experimental observations can be explained by the study of the gas phase. The gas mixture $\mathrm{C}_{2} \mathrm{H}_{2} / \mathrm{H}_{2}(20 \mathrm{sccm} / 80 \mathrm{sccm})$ was simulated, in dependence on CVD mode, to obtain clear view of the influence of hydrogen and hydrocarbon species on the carbon nanotube growth. The number density of some gas phase species on the substrate is shown in Fig. 4. The simulated growth rate and the experimental growth rate are reported in Table 1.

\subsection{Thermal CCVD}

In our conditions, no tubular structures were observed (Fig. 3a). Although acetylene is highly decomposed in the temperature range of $800-900{ }^{\circ} \mathrm{C}$ by the catalytic assistance of $\mathrm{Co}$, the concentrations of carbon monomers $\mathrm{C}$, of dimers $\mathrm{C}_{2}$ and generally of highly dehydrogenated hydrocarbons activated on the surface of the catalytic particles at $700{ }^{\circ} \mathrm{C}$ are small (see Fig. 4). Another factor is the $\mathrm{NH}_{3}$ pretreatment which is essential for etching of Co particles and which induces catalyst particle nucleation. An inefficient pretreatment can prevent growth of CNTs. After efficient treatment, the nanostructures are curly and the growth rate can reach $0.5 \mu \mathrm{m} / \mathrm{min}$ [23]

\subsection{HF CCVD}

In hot filament (heated to $2250 \mathrm{~K}$ ) catalytic CVD method, both SEM (Fig. 3b) and TEM images (not presented here) show that very few but long tubular carbon structures are grown, whereas most of the nanoparticles are fully encapsulated by graphite shells. However, other authors observed dense tangled and curly CNTs or nanofibers [24] with an instantaneous growth rate approaching $40 \mu \mathrm{m} / \mathrm{min}$ [25]. Two reasons can explain this high value: the temperature in the gas phase and on the substrate is high (see Fig. 2) compared to that associated with the thermal CCVD mode and the high dissociation of acetylene and molecular hydrogen by the filaments allow the growth of graphitic sheets nucleating on certain faces of the catalyst particles. Using our model of catalytic surface reactions, a growth rate of $0.5 \mu \mathrm{m} / \mathrm{min}$ is predicted which is in good agreement with our observations. The fact that sometimes CNT growth occurs can be explained by a competition

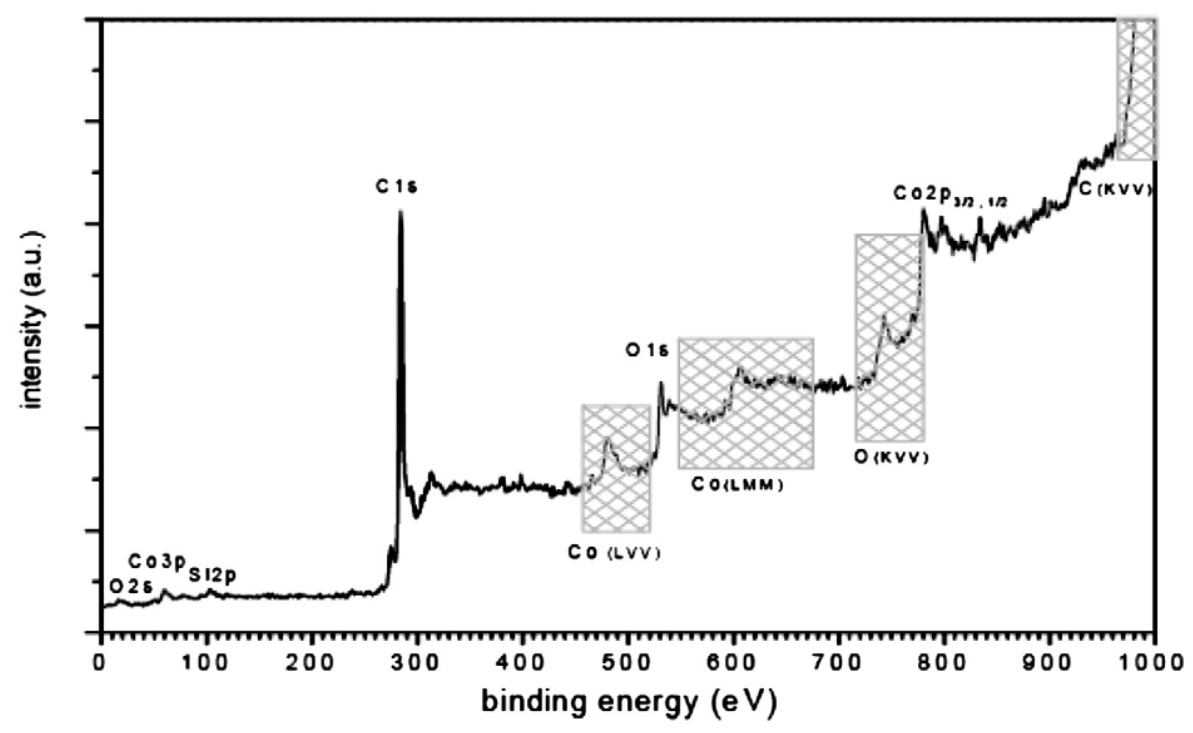

Fig. 5. XPS measurements on C nanostructures deposited by PE CCVD. 
Table 2

\begin{tabular}{lll}
\hline Charged species & $\begin{array}{l}\text { Number density }\left[\mathrm{cm}^{-3}\right] \text { in } \\
\text { PE CCVD }\end{array}$ & $\begin{array}{l}\text { Number density }\left[\mathrm{cm}^{-3}\right] \text { in } \\
\text { PE HF CCVD }\end{array}$ \\
\hline $\mathrm{e}^{-}$ & $1.9 \times 10^{11}$ & $5.6 \times 10^{11}$ \\
$\mathrm{H}^{+}$ & $4.4 \times 10^{9}$ & $3.6 \times 10^{11}$ \\
$\mathrm{H}_{2}^{+}$ & $1.3 \times 10^{10}$ & $1.6 \times 10^{10}$ \\
$\mathrm{CH}_{4}^{+}$ & $1.3 \times 10^{10}$ & $1.3 \times 10^{10}$ \\
$\mathrm{C}_{2} \mathrm{H}_{5}^{+}$ & $1.5 \times 10^{11}$ & $1.5 \times 10^{11}$ \\
\hline
\end{tabular}

between passivation and nucleation. The occurrence of CNT nucleation is generally related to an efficient heat pretreatment [23].

\subsection{PE CCVD}

Small aligned tubular structures were observed in the plasma enhanced CCVD mode (Fig. 3c). Moreover XPS data (Fig. 5) show a high $\mathrm{C}$ deposit, with the absence of any silicon (substrate) signal, compatible with a high and homogeneous growth rate (see Table 1), compared to the thermal CCVD process. This confirms that a high pressure in the discharge (10 mbar) means a high density of carbonaceous precursors associated with a high dissociation due to the increased gas temperature (plasma heating), as observed in Fig. 2 and a low $\mathrm{H}$ content $\left(\mathrm{H}_{2}\right.$ is difficult to dissociate using a DC plasma). Moreover the alignment of the tiny carbon nanostructures is associated with the ions of the plasma issued from the inelastic collisions between electrons and neutral particles. The cathode dark space extends on less than $1 \mathrm{~mm}$, which leads to an electric field higher than $0.1 \mathrm{~V} / \mu \mathrm{m}$ in the cathode sheath. Due to this electric field, the positive ions hit the cathode surface with an energy $(\sim 15 \mathrm{eV})$ sufficient for impeding the growth of nanostructures parallel to the surface [26].

The most abundant charged species in the plasma (in negative glow) are shown in Table 2. The ion current density is assessed from the relation:

$\mathrm{J}_{\mathrm{i}}=\mathrm{en}+\mathrm{v}+$

where $\mathrm{n}_{+}$is the positive ion density and $\mathrm{v}_{+}$is their directional velocity. According to the Bohm sheath criterion, the minimum velocity required for an ion to reach the surface exposed to the plasma is the thermal velocity (also called Bohm velocity) defined by:

$\mathrm{v}_{\text {Bohm }}=\left(\mathrm{kT}_{\mathrm{e}}=\mathrm{m}_{+}\right)_{\mathrm{E}_{2}}$

Where $m_{+}$is the mass of positively charged ions and $T_{e}$ is the electron temperature $(1.6 \mathrm{eV})$.

Experimentally measured current density on the negatively biased sample is $6 \mathrm{~mA} / \mathrm{cm}^{2}$. Taking into account the ion density of the most abundant species in PE CCVD plasma, measured in the negative glow (Table 2), the estimated current density from Eqs. (2) and (3) is $5.5 \mathrm{~mA} / \mathrm{cm}^{2}$, in good agreement with $6 \mathrm{~mA} / \mathrm{cm}^{2}$, which again confirms the correctness of number density evaluation.

Experimental PE CCVD growth rate is found to be $5 \times 10^{-3} \mu \mathrm{m} / \mathrm{min}$ According to Fig. 4, number densities of small radicals in PE CCVD (C, $\mathrm{C}_{2}, \mathrm{CH}, \mathrm{CH}_{2}, \mathrm{C}_{2} \mathrm{H}$ ) are one order of magnitude higher than in thermal CCVD, but are much smaller (several orders of magnitude) compared to HF CCVD. It follows logically that the simulated growth rate for PE CCVD based on our model of gas phase and surface kinetics performed in CHEMKIN software $\left(9 \times 10^{-3} \mu \mathrm{m} / \mathrm{min}\right)$, in good agreement with the experimental value, is higher than for thermal CCVD but much smaller than for HF CCVD (Table 1).

\subsection{PE HF CCVD}

Dense aligned carbon nanotubes (Fig. 6a) were synthesized when plasma enhanced hot-filament catalytic chemical vapor deposition was used (Fig. 3d), as confirmed by other studies [24]. TEM image of an individual nanotube (Fig. 6b) clearly shows that it is a multi-walled CNT with an outer diameter around $50 \mathrm{~nm}$. The length of CNTs was estimated at $6 \mu \mathrm{m}$, leading to an experimental growth rate of $0.4 \mu \mathrm{m} / \mathrm{min}$, which is of the same order of magnitude with the simulated value of $0.8 \mu \mathrm{m} / \mathrm{min}$. Such a high growth rate, compared to PE CCVD process, is the result of a combination of HF process on the one hand generating high densities of atomic hydrogen acting as chemical etchant of a-C:H (which corresponds to a pre-nucleation step) and also favoring high densities of carbon species $\left(\mathrm{C}, \mathrm{C}_{2}\right)$ and of small hydrocarbons $\left(\mathrm{CH}, \mathrm{CH}_{2}, \mathrm{CH}_{2}(\mathrm{~S}), \mathrm{C}_{2} \mathrm{H}\right)$ which are the growth precursors, and of $\mathrm{PE}$ process on the other hand generating ions impinging the substrate surface, which leads to the CNT alignment. It must be noted that the densities of large hydrocarbons $\left(\mathrm{C}_{2} \mathrm{H}_{4}, \mathrm{C}_{2} \mathrm{H}_{5}\right.$, $\mathrm{C}_{2} \mathrm{H}_{6}$ ), supposed to be at the origin of the catalyst deactivation, so playing the role of catalyst poisoners, are almost the same whatever the CCVD activation mode may be.

\subsection{Effect of the $\mathrm{C}_{2} \mathrm{H}_{2}$ partial pressure in the PE HF CCVD mode}

The study of partial pressure of acetylene on growth rate is shown in Fig. 7. It can be seen that growth rate starts to saturate after $25 \%$ of $\mathrm{C}_{2} \mathrm{H}_{2}$ in the gas inlet mixture, indicating that $20 \%-25 \%$ a-cetylene is the ideal amount for CNT growth in these conditions, which is in good agreement with other investigations [27]. This effect can be explained by observing how the ratio of less hydrogenated hydrocarbons $\left(\mathrm{C}_{\mathrm{x}} \mathrm{H}_{\mathrm{y}}, \mathrm{x} / \mathrm{y} \geq 0.5\right)$ to more hydrogenated hydrocarbons $\left(\mathrm{C}_{\mathrm{x}} \mathrm{H}_{\mathrm{y}}, \mathrm{x} / \mathrm{yb} 0.5\right)$ evolves with $\mathrm{C}_{2} \mathrm{H}_{2}$ pressure. This ratio (plotted in the right scale of Fig. 7) starts to saturate, as well as the growth rate, at around the same value of $\mathrm{C}_{2} \mathrm{H}_{2}$ partial pressure (30\%). It can be (a)

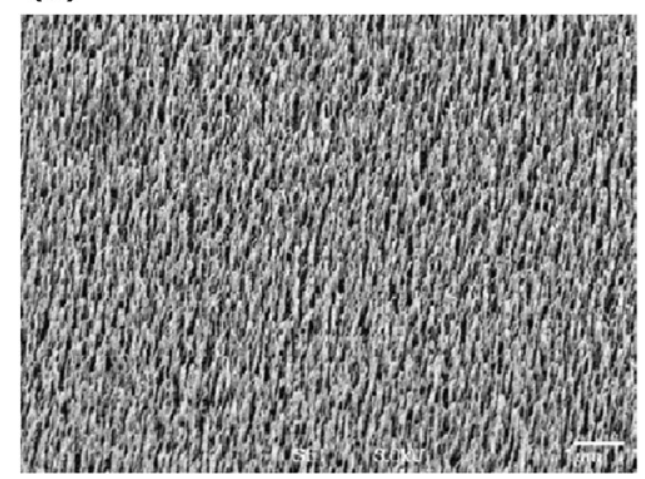

(b)

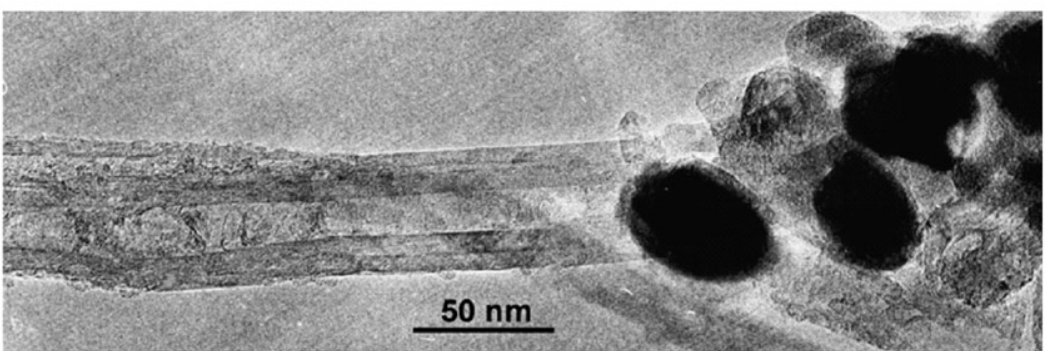




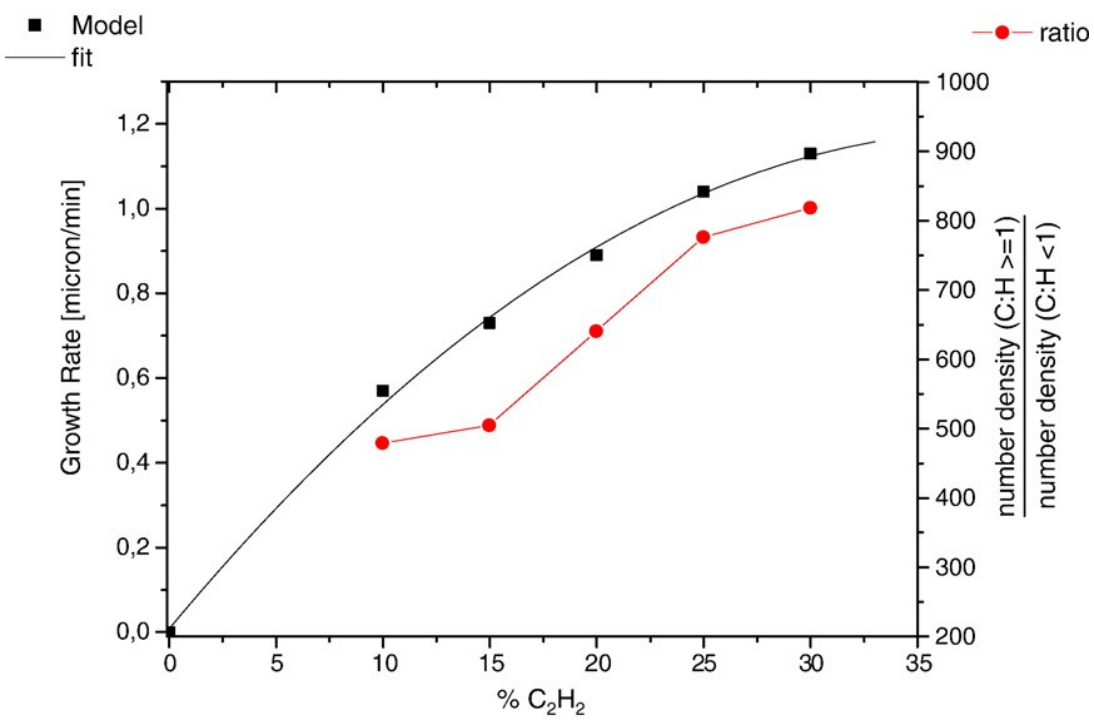

Fig. 7. Growth rate and calculated $\mathrm{C}_{2}$ density versus percentage of $\mathrm{C}_{2} \mathrm{H}_{2}$ in feed mixture.

inferred from this curve that the less hydrogenated hydrocarbons (the growth precursors) are competing with the more hydrogenated hydrocarbons (the species involved in the deactivation and encapsulation of the catalytic particles) for the catalytic activity or poisoning.

\section{Summary}

Four CCVD modes (thermal, plasma-enhanced, hot-filament and plasma-enhanced hot- filament) were studied experimentally and simulated, using gas phase and surface kinetic simulations taking into account optical emission spectroscopy data, to estimate carbon nanotube growth precursors. $\mathrm{C}_{2} \mathrm{H}_{2} / \mathrm{H}_{2}$ gas mixture has been considered in each of the four CCVD modes. In summary:

- in thermal CCVD, inlet gases are insufficiently dissociated, so the density of active carbon species is low. Consequently the growth rate is very low and can be cancelled if the $\mathrm{H}_{2}$ pretreatment, which is a critical step, is not controlled.

- in HF CCVD, $\mathrm{C}_{2} \mathrm{H}_{2}$ and $\mathrm{H}_{2}$ are highly dissociated in the vicinity of the hot filaments, generating high density of atomic hydrogen, small carbon species and less hydrogenated hydrocarbons, which are believed to be the growth precursors. Thus high growth rate is possible. However rapid encapsulation of the catalytic nanoparticle can occur, leading to a poisoning of the catalyst. If CNT growth occurs, tangled and curly CNTs are generally observed unless steric hindrance between the nanotubes at the initial stage of growth (in the case of very dense CNTs) force them to align vertically.

- in PE CCVD, $\mathrm{C}_{2} \mathrm{H}_{2}$ is not highly dissociated by the plasma $\left(\mathrm{H}_{2}\right.$ is not dissociated); however to a lesser extent $\mathrm{CN}$ radicals are generated, which act as etchants of graphite. So the growth rate is much smaller than for HF CCVD process. The presence of positive ions crossing the cathode sheath obliges the CNTs to align perpendicularly to the substrate.

- in PE HF CCVD, $\mathrm{C}_{2} \mathrm{H}_{2}$ and $\mathrm{H}_{2}$ are highly dissociated either by the plasma for $\mathrm{C}_{2} \mathrm{H}_{2}$ or by hot filaments for $\mathrm{C}_{2} \mathrm{H}_{2}$ and $\mathrm{H}_{2}$. High densities of $\mathrm{H}$, small carbon species $\left(\mathrm{C}, \mathrm{C}_{2}\right)$ and less hydrogenated hydrocarbons
$\left(\mathrm{CH}, \mathrm{CH}_{2}, \mathrm{CH}_{2}(\mathrm{~S}), \mathrm{C}_{2} \mathrm{H}\right)$ are generated. Moreover due to the electric field in the cathode sheath, the positive ions hit the cathode surface. Thus dense well-aligned CNTs are grown with a high growth rate.

\section{References}

[1] M.S. Dresselhaus, G. Dresselhaus, P. Avouris, Carbon Nanotubes: Synthesis, Structure, Properties and Applications, vol. 29, Springer, Berlin, 2001.

[2] A. Loiseau, X. Blase, J.C. Charlier, P. Gadelle, C. Journet, C. Laurent, P. Peigney, Understanding Carbon Nanotubes: From Basics to Applications, Lecture Notes in Physics, vol. 677, Springer, Berlin, 2006, p. 49.

[3] R.T.K. Baker, P.S. Harris, R.B. Thomas, R.J. Waite, J. Catal. 26 (1972) 51

[4] P.T.A. Reilly, Carbon 44 (2006) 1653.

[5] S. Helveg, C. Lopez-Cartes, J. Sehested, P.L. Hansen, B.S. Clausen, J.R. RostrupNielsen, F. Abild-Pedersen, J.K. Norskov, Nature 427 (2004) 426.

[6] A. Moisala, A.G. Nasibulin, E.I. Kauppinen, J. Phys.: Condens. Matter 15 (2003) S3011

[7] O.A. Louchev, J. Chem. Phys. 118 (2003) 7622.

[8] F. Ding, Chem. Phys. Lett. 393 (2004) 309.

[9] D. Hash, M.S. Bell, K.B.K. Teo, B.A. Cruden, W.I. Milne, M. Meyyappan, Nanotechnology 16 (2005) 925.

[10] K. Kuwana, Chem. Eng. Sci. 61 (2006) 6718.

[11] B.A. Cruden, A.M. Cassell, D.B. Hash, M. Meyyappan, J. Appl. Phys. 96 (2004) 5284

[12] M. Grujicic, G. Cao, B. Gersten, Mater. Sci. Eng. B94 (2002) 247.

[13] M.P. Cabero, J. Catal. 224 (2004) 197.

[14] M.M. Larijani, A. Navinrooz, F. Le Normand, Thin Solid Films 501 (2006) 206.

[15] C.S. Cojocaru, F. Le Normand, Thin Solid Films 515 (2006) 53.

[16] C.S. Cojocaru, A. Senger, F. Le Normand, J. Nanosci. Nanotechnol. 6 (2006) 1331.

[17] P. Veis, C.S. Cojocaru, F. Le Normand, Acta Phys. Univ. Comen. XLIV-XLV (2004) 95

[18] R.J. Kee, F.M. Rupley, J.A. Miller, et al., CHEMKIN Release 4.0.2, Reaction Design, San Diego, CA, 2005.

[19] M. Gulas, C.S. Cojocaru, F. Le Normand, S. Farhat, Plasma Chem. Plasma Process. 28 (2008) 123.

[20] K.B.K. Teo, et al., Nano Lett. 4 (2004) 921.

[21] A. Mankelevich, A.T. Rakhimov, N.V. Suetin, Diamond Relat. Mater. 7 (1998) 1133.

[22] J.Y. Juang, Diamond Relat. Mater. 13 (2004) 1203.

[23] C.J. Lee, et al., Chem. Phys. Lett. 312 (1999) 461.

[24] C.S. Cojocaru, D. Kim, D. Pribat, J.E. Bourée, Thin Solid Films 501 (2006) 227.

[25] S. Lee, S. Choi, K.H. Park, K.W. Chae, J.B.Cho, Y. Ahn, J.Y.Park, K.H. Koh, Thin Solid Films 516 (2008) 700.

[26] D. Kim, S.H. Lim, A.J. Guilley, C.S. Cojocaru, J.E. Bourée, L. Vila, J.H. Ryu, K.C. Park, J. Jang, Thin Solid Films 516 (2008) 706.

[27] M.S. Bell, et al., Appl. Phys. Lett. 85 (2004) 7 